VISUAL EXPERIMENT

\title{
Estimation of Arsenic in Nail using Silver Diethyldithiocarbamate Method
}

\section{Habiba Akhter Bhuiyan, Kipchu Tshering and Mir Misbahuddin}

Division of Arsenic Research, Department of Pharmacology, Faculty of Basic Science and Paraclinical Science, Bangabandhu Sheikh Mujib Medical University, Shahbag, Dhaka, Bangladesh.

Correspondence to Mir Misbahuddin at mmisbah@bsmmu.edu.bd

First Published: 1 July, 2015; Updated version: 1.0

DOI: 10.3329 /bjp.v10i3.23644

\section{ABSTRACT}

Spectrophotometric method of arsenic estimation in nails has four steps: a) washing of nails, b) digestion of nails, c) arsenic generation, and finally d) reading absorbance using spectrophotometer. Although the method is a cheapest one, widely used and effective, it is time consuming, laborious and need caution while using four acids.

\section{INTRODUCTION}

Estimation of total arsenic in water and biological samples are important for the diagnosis of arsenicosis (Misbahuddin, 2015). Biological samples include blood, urine, hair and nail. The normal amount of arsenic in blood is very low and requires sophisticated instrument to detect. Presence of arsenic in urine indicates recent exposure of arsenic. Absence of arsenic in urine sometimes does not exclude the diagnosis of arsenicosis. High concentration of arsenic in hair and nail indicates chronic exposure. The accumulation of arsenic in hair is less than the nail. There is superstition in some countries not to give hair sample. Compared to urine or blood samples, nails have the advantage of facilitating specimen collection, storage, and transportation. Therefore, the estimation of arsenic in nail is the preferred biological sample for easy collection (Karagas et al., 1996).

Estimation of arsenic in nail can be done using spectrophotometer, atomic absorption spectrometer with hydride generator (AAS-HG), High performance liquid chromatography with hydride generation with atomic fluorescence spectrometer (HPLC-HG-AFS), inductively coupled plasma-mass spectrometry (ICPMS) (Chen et al., 1999), proton particle-induced X-ray emission and neutron activation analysis. Among these methods spectrophotometric method using silver diethyldithiocarbamate (SDDC) is still an effective, widely used and cheapest method.

In this method, arsenic reacts with zinc in presence of acid to produce arsine gas $\left(\mathrm{AsH}_{3}\right)$ which is scrubbed through lead acetate impregnated glass wool (remove hydrogen sulfide) and is absorbed in SDDC dissolved in hexamethylenetetramine. The red color developed due to arsine silver diethyldithiocarbamate reaction is measured by spectrophotometer at wavelength of $535 \mathrm{~nm}$.

\section{PREPARATION OF REAGENTS}

Arsenic trioxide stock solution ( $1 \mathrm{mg} / \mathrm{mL}$ ): One hundred and thirty two milligram of arsenic trioxide (Mr. 198; E. Merck, Germany) is taken in a $100 \mathrm{~mL}$ beaker. About $50 \mathrm{~mL}$ of deionized distilled water was added to it and stirred. Arsenic is not dissolved in water. It is either dissolved in alkaline $\mathrm{pH}$ or hot water. Thus, $5 \mathrm{~N}$ $\mathrm{NaOH}$ is added drop by drop till arsenic trioxide dissolves completely. Subsequently deionized distilled water is added up to $100 \mathrm{~mL}$. So, the concentration of the prepared solution was $1 \mathrm{mg} / \mathrm{mL}$. It is then kept in amber colored bottle for storage (longer period) at $0-4^{\circ} \mathrm{C}$. Nitrogen gas may be administered to the bottle, each time when the bottle is opened. From this stock solution, working solution is prepared daily by dilution. 
Lead acetate solution (10\%): Ten gram of lead acetate (Mr. 325; Loba Chemie, India) is dissolved in a $100 \mathrm{~mL}$ measuring cylinder with deionized distilled water up to the mark. It is then kept at room temperature before use.

Potassium iodide solution (15\%): Fifteen gram of potassium iodide (Mr. 166; BDH Chemical, UK) is taken in a $100 \mathrm{~mL}$ measuring cylinder with deionized distilled water up to the mark. It is then kept at room temperature before use.

Stannous chloride solution (40\%): Forty gram of stannous chloride solution (Mr. 190; Loba Chemie, India) is dissolved in $50 \mathrm{~mL}$ of hot water. The solution is filtered in a $100 \mathrm{~mL}$ measuring cylinder after cooling. Then concentrated hydrochloric acid is added up to the mark. It is kept at room temperature before use.

SDDC solution (0.5\%): Five hundred milligram of SDDC (Mr. 256; E. Merck, Germany) and $3 \mathrm{~g}$ of hexamethylenetetramine (Mr. 140; E. Merck, Germany) is taken in $100 \mathrm{~mL}$ measuring cylinder and chloroform is added up to the mark. Then it is stirred to mix properly and filtered in an amber colored bottle. The solution is kept in the refrigerator at $0-4^{\circ} \mathrm{C}$ before use. This reagent is used as an absorber for the arsenic.

\section{CLEANING GLASSWARE}

Glassware is washed in detergent solution, rinsed with tap water, and then soaked for 24 hours in $20 \%$ $(\mathrm{v} / \mathrm{v})$ nitric acid. After soaking, glassware is rinsed with deionized water and oven-dried for 24 hours at $50^{\circ} \mathrm{C}$

\section{VIDEO CLIPS}
Nail wash:
$3.2 \mathrm{~min}$
Digestion of nail:
$7.0 \mathrm{~min}$
Arsine generation: $10.0 \mathrm{~min}$
Reading absorbance: $1.2 \mathrm{~min}$

\section{METHOD}

Nail wash

1. Clean the nails with distilled water $(3 \mathrm{~mL})$ in a small beaker $(10 \mathrm{~mL}$ size $)$ and sonicate for $2 \mathrm{~min}$. Repeat the process.

2. Transfer the nails to petri dish $\left(4^{\prime}\right.$ size $)$ containing acetone $(3 \mathrm{~mL})$ and maintain it for $1 \mathrm{~min}$ in order to remove external contamination of arsenic.

3. Wash the nails again with deionized water to remove trace amount of acetone.

4. Allow the nails to dry (at room temperature). It usually takes 1 to 2 hours.

5. Weigh the nail by an electronic balance. The minimum weight of nails must be more than $200 \mathrm{mg}$.

\section{Digestion}

6. Place the nails within a conical flask $\left(100 \mathrm{~mL}\right.$ size; $\left.\mathrm{S}_{1}\right)$.

7. Take two other conical flasks. One for reagent blank (B) and the other for the standard (Std).

8. Add nitric acid $(0.3 \mathrm{~mL})$, sulfuric acid $(3 \mathrm{~mL})$ and perchloric acid $(1 \mathrm{~mL})$ into all the three flasks.

9. Place the flasks in an arsenic digestion unit.

10. Digest the nails and others until white fume $\left(\mathrm{SO}_{3}\right)$ disappear within the flasks. It usually takes $30 \mathrm{~min}$.

11. Wait for 1 to 1.5 hours to cool the flask.

\section{Generation}

12. Take distilled deionized water $(25 \mathrm{~mL})$ into three conical flasks $(250 \mathrm{~mL})$ with stopper. 
13. Transfer the digested solution to the corresponding conical flask slowly.

14. Add hydrochloric acid ( $3 \mathrm{~mL})$ to each flask.

15. Add $15 \%$ potassium iodide solution $(50 \mu \mathrm{L})$ to each flask. The solution within the flask will be changed to yellow color.

16. Add $40 \%$ stannous chloride (ranging from 10 to $200 \mu \mathrm{L}$ ) to each flask until the solution becomes clear.

17. Soak cotton with $10 \%$ lead acetate $(200 \mu \mathrm{L})$.

18. Add SDDC solution (3-3.5 mL) in the generation tube.

19. Add zinc ( $5 \mathrm{~g})$ at the solution. Reaction will start. The color of the solution in arsine generator will be changed to red if there is arsenic.

20. Collect the solution from the arsine generator into the corresponding test tubes with trace amount of anhydrous sodium sulfate (to absorb air). Visual adjustment of the volumes of all test tubes with chloroform.

Reading absorbance

21. Switch on the spectrophotometer.

22. Place the solution in a cuvette $(1 \mathrm{~cm})$.

23. Keep the cuvette within the spectrophotometer.

24 . Take reading using the spectrophotometer at $535 \mathrm{~nm}$.

\section{EQUIPMENT}

Arsenic digestion unit

Arsine generator

Electronic balance

Magnetic stirrer with teflon

Digital pipette with tip and glass pipette with aid

Spectrophotometer with cuvette

\section{CALCULATION}

The absorbance of standard (Std) solution of arsenic trioxide $(20 \mu \mathrm{L}$ of $1 \mathrm{mg} / \mathrm{mL})$ after deduction of the blank is 0.732 . On the other hand, the absorbance of the sample $\left(\mathrm{S}_{1}\right)$ after deduction of the blank is 0.451 .

Absorbance 0.732 for arsenic $=20 \mu \mathrm{g}$

Absorbance 0.001 for arsenic $=20 \mu \mathrm{g} / 0.732$

Absorbance 0.451 for arsenic $=(20 \mu \mathrm{g} / 0.732) \times 0.451=12.3 \mu \mathrm{g}$

Therefore,

$276.5 \mathrm{mg}$ of nail sample contains arsenic $=12.3 \mu \mathrm{g}$

$1 \mathrm{mg}$ of nail sample contains arsenic $=12.3 \mu \mathrm{g} / 276.5$

$1000 \mathrm{mg}$ of nail sample contains arsenic $=(12.3 \mu \mathrm{g} / 276.5) \times 1000=44.5 \mu \mathrm{g} / \mathrm{g}$

\section{DISCUSSION}

The normal level of arsenic in nail is less than $1 \mu \mathrm{g} / \mathrm{g}$ of nail. It is due to ingestion of arsenic through food. Foodstuff contains low level of arsenic. In arsenic endemic area like Bangladesh, high concentration of arsenic is present within the drinking water and foodstuff. Peoples living in this area have high level of arsenic in nails. The level of arsenic in nails of the people living in arsenic affected area has more than 1 $\mu \mathrm{g} / \mathrm{g}$. 
Both fingernails and toenails are used for the estimation of arsenic. The growth of fingernails (4-5 $\mathrm{mm} / \mathrm{month})$ is faster than the toenails $(1.1 \mathrm{~mm} / \mathrm{month})$. Justification of using toenail is the chance of less contamination with arsenic contaminated water. Some investigators prefer to use toenails whereas others prefer to use both toenails and fingernails. We prefer to use both fingernails and toenails for the estimation of arsenic in nails. Nails have high concentration of keratin containing $-\mathrm{SH}$ group. Arsenic has high affinity to bind with -SH group.

The estimation of accurate amount of arsenic in nail not only depends on the method of estimation but also depends on washing procedure. Nails are contaminated with external sources. Hands and legs must be cleaned with water before clipping of nails. Avoid normal blade to collect nails. Instead stainless steel clippers are preferred.

An ideal method of washing nails should be to remove surface contamination without depleting the arsenic within the nail structure. Wash of nails can be done by distilled deionized water, detergent and organic solvent. The preferred method of washing is to sonicate nails in presence of water. Washing nail with acetone is to remove organic contaminant on the surface of nail (Schmitt et al., 2005). Lastly, use water to remove the acetone and loosen or dissolve surface contaminants (Karagas et al., 1996). Washing with Triton X-100 (2\%) for 20 min may reduces the amount of arsenic in nail (Chen et al., 1999). Excessive exposure of nail to acetone should be avoided.

The nails may be dried either in open air or at oven dried at approximately $50^{\circ} \mathrm{C}$ before being weighed.

The nails contain both inorganic and organic arsenic. Digestion of nails with acids is necessary in order to release organic arsenic bound to nails. Thus, we can accurately estimate the total arsenic in nail. Digestion can be done either by open method, microwave or teflon digestion bomb. There is every chance to lose arsenic into the air while digested in open method. To avoid this, teflon digestion bomb is the best option. However, it is expensive.

We have used three acids for digestion of nails. Two acids (nitric acid and perchloric acid) can also be used (Ghanthimathi et al., 2012). The ratio of nitric acid to perchloric acid varies from authors to authors. It may be $5: 2,3: 2,7: 2$, or $7: 1$.

In this method, SDDC is dissolved in chloroform containing hexamethylenetetramine. Some laboratories prefer to dissolve SDDC in pyridine. However, the role of pyridine as carcinogen is not clear.

Inter-day variability of arsenic measurements is not significant across a week after acid digestion (Chen et al., 1999).

\section{REFERENCES}

Chen KLB, Amarasirlwardena CJ, Christian DC. Determination of total arsenic concentrations in nails by inductively coupled plasma mass spectrometry. Biol Trace Element Res. 1999; 67: 109-25.

Ghanthimathi S, Aminah A, Salmijah S, Ujang T, Nurul Izzah A. Comparison of microwave assisted acid digestion methods for ICP-MS determination of total arsenic in fish tissue. Sains Malaysiana 2012; 41: 1557-64.

Karagas MR, Morris JS, Weiss JE, Spate V, Baskett C, Greenberg ER. Toenail samples as an indicator of drinking water arsenic exposure. Cancer Epidemiol Biomarkers Prev. 1996; 5: 849-52.

Misbahuddin M. Arsenicosis: A global issue. California, Science Publishing Group. 2015.

Schmitt MT, Schreinemachers D, Wu K, Ning Z, Zhao B, Le XC, Mumford JL. Human nails as a biomarker of arsenic exposure from well water in Inner Mongolia: Comparing atomic fluorescence spectrometry and neutron activation analysis. Biomarkers. 2005; 10: 95-104.

Slotnick MJ, Meliker JR, AvRuskin GA, Ghosh D, Nriagu JO. Toenails as a biomarker of inorganic arsenic intake from drinking water and foods. J Toxicol Environ Health, Part A. 2007; 70: 148-58.

\section{CAUTION}

Acetone: Acetone is very flammable. Do not use it around flames. Exposure to acetone can cause eye irritation, dryness of the mouth and throat, nausea, vomiting, headache, sleepiness, dizziness, weakness and fainting.

Arsenic trioxide: Arsenic trioxide should be stored in a safe place of the laboratory under lock and key in order to ovoid suicidal or homicidal incidence. Mask and hand gloves should be used during weighing of arsenic trioxide.

Hexamethylenetetramine (Hexamine): It has foul odor. 
Hydrochloric acid: Take safety precautions for handling concentrated hydrochloric acid. Use gloves and goggles to avoid contact with skin and eyes. Use an effective fume removal device or other respiratory protection. Use caution and always add acid slowly to water. It is corrosive to skin, metals, and clothing. Avoid contact with liquid and vapor.

Lead acetate: Use gloves and goggles to avoid contact with skin and eyes.

Nitric acid: Take safety precautions for handling concentrated nitric acid. Use gloves and goggles to avoid contact with skin and eyes. Use an effective fume removal device or other respiratory protection. Use caution and always add acid slowly to water. It is corrosive to skin, metals, and clothing. Avoid contact with liquid and vapor. When removing trace metal contaminants from pipette tips or reaction vials with 1:1 concentrated nitric acid: $\mathrm{ddH}_{2} \mathrm{O}$, make sure no organic solvents like ethanol or diethyl ether are inadvertently mixed with the nitric acid waste. An explosion may occur when this happened at a lab using this procedure.

Perchloric acid: Perchloric acid is a strong mineral acid. Under some circumstances, it may act as an oxidizer and/or present an explosion hazards. It is a highly corrosive substance and causes severe burns on contact with the eyes, skin, and mucous membranes. The quantity of perchloric acid kept in storage purpose should be minimum. It should be stored in its original container preferably glass or porcelain. Perchloric acid should be separate from other chemicals, but may be stored with other inorganic acids, preferably in a metal cabinet designed for acid/corrosive storage. It must be stored away from organic chemicals, flammable or combustible materials and strong dehydrating agents such as sulfuric acid. If a bottle containing perchloric acid has turned dark and has crystals forming around the bottom of the bottle, there is a potential explosion hazard. Use dilute solutions $(<60 \%)$ whenever possible.

Sulfuric acid: Take safety precautions for handling concentrated sulfuric acid. Use gloves and goggles to avoid contact with skin and eyes.

Never pipette solutions using mouth suction. This method is not sterile and can be dangerous. Always use a pipette aid or bulb. 